REGIONAL STATISTICS, 2013, VOL. 3: 41-56 DOI: 10.15196/RS03103

ÁRON KINCSES ${ }^{\text {a) }}-$ GÉZA TÓTH $^{\text {b) }}$

\title{
Investigation of spatial structure: modelling approach ${ }^{*}$
}

\begin{abstract}
In this paper the authors wish to introduce an application of the gravitational model through a concrete example. In their investigation the gravitational model was transformed to analyse the impact of accessibility in a way, that not only the size of gravitational forces but their direction can also be measured. Displacements were illustrated by a bi-dimensional regression, which gives a new perspective to the investigation of the Hungarian spatial structure.
\end{abstract}

Keywords: gravitational model, bi-dimensional regression, accessibility, spatial structure, Hungary.

\section{Introduction}

The overall goal of modelling is to simplify reality, actual processes and interactions and on the basis of the obtained data to draw conclusions and make forecasts. Models based on gravitational analogy are the tools of spatial interactions of classical regional analyses. They were first applied in the 19th century (Carey 1858, Reilly 1929, Stewart 1948, Converse 1949, Zipf 1949, Dodd 1950, Hammer-Ikle 1957, etc.).

The application of the geographical gravity is confirmed by the theory of experience according to which (just as in time) the things that are closer to each other in space are more related than distant things. This is called the "first law of geography" (Tobler 1970).

There are two basic areas of the application of gravitational models based on physical analogy: the spatial flow analysis (Filippo, S. et al. 2012, Martinez et. al. 2003), and the demarcation of catchment areas (Vieira et al. 1993, Mate et al. 2011). The potential models based on gravitational analogy are the most important groups of accessible models. In general, it can be stated that they are accessible approaches according to which models show potential benefits of the region compared to other regions where the benefits are quantified (Spiekermann-Wegener-Schürmann 1997).

The use of accessible models in transport-geographical studies is very common. However, when models are used, it is not entirely clear what is actually modelled;

a) Hungarian Central Statistical Office, 1024 Budapest, Keleti Károly út 5-7., Hungary, E-mail: aron.kincses@ksh.hu b) Hungarian Central Statistical Office, 1024 Budapest, Keleti Károly út 5-7., Hungary, E-mail: geza.toth@ksh.hu

* In this paper the authors wish to introduce an application of the gravitational model through a concrete example. In their investigation the gravitational model was transformed to analyse the impact of accessibility in a way, that not only the size of gravitational forces but their direction can also be measured. Displacements were illustrated by a bi-dimensional regression, which gives a new perspective to the investigation of the Hungarian spatial structure. 
because of their complexity their interpretations may be difficult (Kincses-Tóth 2011). It should be stressed that accessibility has no universally accepted definition; in empirical studies different methodological background indicators are used (see Geurs-van Wee 2004, Gutierrez 2001, Tschopp et al. 2003, Willigers-Floor-van Wee 2007). The gravitational theory is a theory of contact, which examines the territorial interaction between two or more points in a similar way as correlations are analysed in the law of gravitation in physics. According to Dusek (2003), despite the analogy, there are significant differences between gravitational models used by social sciences and the law of gravitation used in physics. It is worth bearing in mind that "the gravitational model is not based on the gravitational law". It is a fundamental statement based on the experience of undeniable statistical character that takes into consideration spatial phenomena. According to this statement, phenomena interact with each other. The phenomena, which are closer to each other in space, are more related than distant phenomena (Dusek 2003, p. 45.).

There are a number of differences between the law and the model. In this study, we wish to highlight a new point of view. As a consequence of the spatial interaction, classical gravitational potential models show the magnitude of potential at spatial points. Regarding the law of gravity in physics, the direction of forces cannot be evaded. In our approach each unit area is assigned an attraction direction. That is, in the case of the gravity model (although such spaces are free of vortex) the space is characterized using vectors.

\section{Method}

The universal gravitational law, Newton's gravitational law, states (1686) that any two point-like bodies mutually attract each other by a force, whose magnitude is directly proportional to the product of the bodies' weight and is inversely proportional to the square of the distance between them (Budo 1970) (1st formula):

$$
F=\gamma \cdot \frac{m_{1} \cdot m_{2}}{r^{2}}
$$

where $\gamma$ is the proportional factor, the gravitational constant (independent of time and place).

If $r$ indicates the radius vector drawn from the mass point number 2 to a mass point number 1 , then $r / r$ is the unit vector drawn from 1 towards 2 , thus, the impact of gravitational force on mass point 1 from mass point 2 is in (Equation 2) (Figure 1), which reads

$$
\vec{F}_{1,2}=-\gamma \cdot \frac{m_{1} \cdot m_{2}}{r^{2}} \cdot \frac{\vec{r}}{r}
$$

A gravitational field is set if the gradient $(K)$ can be specified by a direction and magnitude in each point of the range. Since $K$ is a vector quantity, three numbers (two in plane) are required to be known at each point, for example the right angle components of gradient $K_{x}, K_{y}, K_{z}$, which are functions of the site. However, many fields, including the gravitational field, can be characterized in a more simple way. They can be expressed by a single scalar, the so-called potential function, instead of three values. 


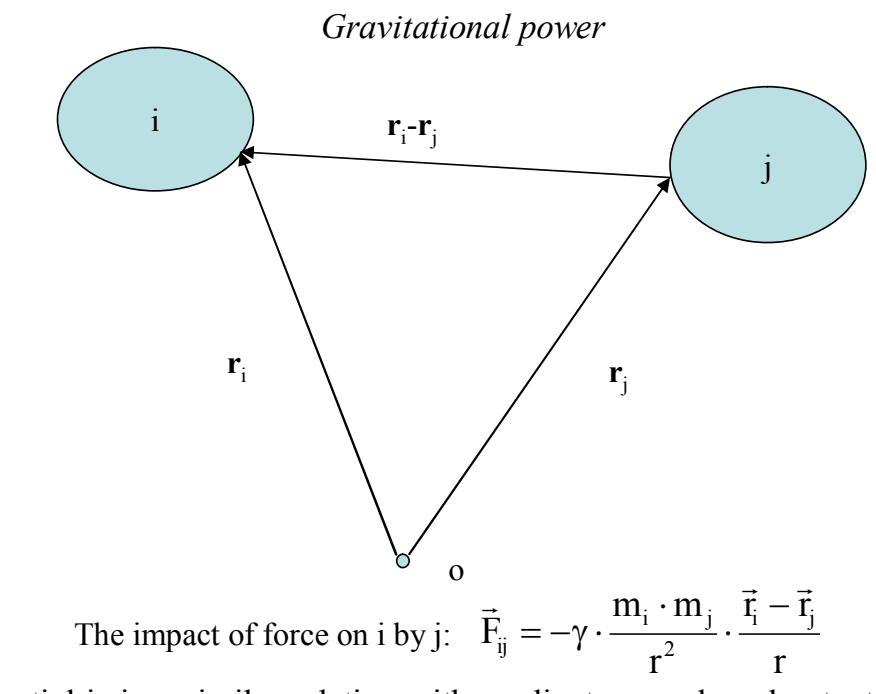

Figure 1

The potential is in a similar relation with gradient as work and potential energy with force.

Taking advantage of this, gravitational models are also applied in most social sciences where space is usually described by a single scalar function, (Kincses-Tóth 2011), whereas in gravitational law vectors characterizing the space are of great importance. The primary reason for this is that arithmetic operations calculated with numbers are easier to handle than with vectors. Perhaps, we could say that by working with potentials we can avoid calculation problems in problem solving. The potential completely characterizes the whirl-free gravity gravitational field, because there is a definite relationship between the field strength and the potential:

$$
\vec{K}=-\operatorname{grad} U \Rightarrow \quad K_{x}=-\frac{\partial U}{\partial x} ; \quad K_{y}=-\frac{\partial U}{\partial y} .
$$

In other words, the potential (as mathematical functional) is the negative gradient of field strength. Various types of potentials and models, which are different from the ones directly based by the gravitational analogy, but in this case, force effects among space power sources are quite different. In fact, these models differ from each other since the attractive forces remain above a predetermined limit value and within set distances.

The force in a general form is:

$$
|\vec{F}|=C \frac{m_{1}^{\alpha} m_{2}^{\beta}}{r^{\gamma}},
$$

where $C, \alpha, \beta$, $\square$ are constants (Barthélemy 2011).

However, how they describe actual power relations between social masses is another question.

Although potential models often characterize concentration on focal points of areas and spatial structures, they fail to provide information in which direction and with how much force the social attributes of other areas attract each delimited area unit. Thus, we 
attempt to use vectors in order to show the direction where the Hungarian micro regions ${ }^{3}$ tend to attract micro regions (LAU1) in the economical space compared to their actual geographical position. This analysis can demonstrate the most important centres of attraction, or discrepancies, and the differences between the gravitational orientations of micro-regions can be displayed on a map after the evaluation of data from 2000, 2005 and 2010 has been performed. In the study the geometric centres of specific microregions were the co-ordinates of Hungarian micro-regions, which were determined in the EOV co-ordinate system ${ }^{4}$ by (Geographical Information System) GIS software.

Our goal can be reached by using Equation (3) to potentials or directly with the help of forces. We chose the latter one.

In the conventional gravity model (Stewart, 1948) $D_{i j}$ is the "demographic force" between $i$ and $j$ where $W_{i}$ and $W_{j}$ are the population size of the settlements (regions), $d_{i j}$ is the distance between $i$ and $j$, and finally, $g$ is the empirical constant (Equation 5).

$$
D_{i j}=g \cdot\left(\frac{W_{i} \cdot W_{j}}{d_{i j}^{2}}\right)
$$

In this study, first the $W_{i}$ and $W_{j}$ weight factors represent personal income, which is the gross income serving as basis of the personal income tax, dij is the actual distance between $i$ and $j$ regional centres measured on road by a minute (regardless of the traffic conditions and only the maximum speed depending on the road type is taken into consideration). The personal income is the best variable to represent the Hungarian spatial development structure. Later the weight factors will be represented by other variables, which are to model the underlying causes of changes in the development.

By generalizing the aforementioned formula, we write the following equation (Equation 6 and 7):

$$
\begin{aligned}
& D_{i j}=\left|\vec{D}_{i j}\right|=\frac{W_{i} \cdot W_{j}}{d_{i j}^{c}} \\
& \vec{D}_{i j}=-\frac{W_{i} \cdot W_{j}}{d_{i j}^{C+1}} \cdot \vec{d}_{i j}
\end{aligned}
$$

where $W_{i}$ and $W_{j}$ are the masses, $d_{i j}$ is the distance between them, $c$ is a constant, which is the change of the intensity of inter-regional relations as a function of distance. As the exponent, $c$, increases and the intensity of inter-regional relations becomes more sensitive to distance, this significance of masses gradually decreases (Dusek 2003). The minus sign express mathematically, that the masses attract each other (see Figure 1).

With the extension of the above Equation we cannot only measure the strength of the force between the two regions, but its direction as well.

3 A micro-region code is the code of a (non- administrative) breakdown covering the whole area of Hungary, which is based on real connections between settlements in terms of work, residence, transport, medium-level provision (education, health care, trade) etc. Through their connections settlements are attracted by one or more central settlements in the system of statistical micro-regions.

4 The EOV is a plane projection system used uniformly for the Hungarian civilian base maps and, in general, for spatial informatics. Geometric classification: Conformal cylindrical projection in transversal position. 
While performing calculations, it is worth dividing the vectors into $x$ and $y$ components and summarize them separately. To calculate the magnitude of this effect (vertical and horizontal forces of components) the following Equations are required (Equation 8 and 9), which follow from (6):

$$
\begin{aligned}
& D_{i j}^{X}=-\frac{W_{i} \cdot W_{j}}{d_{i j}^{c+1}} \cdot\left(x_{i}-x j\right) \\
& D_{i j}^{Y}=-\frac{W_{i} \cdot W_{j}}{d_{i j}^{c+1}} \cdot\left(y_{i}-y_{j}\right)
\end{aligned}
$$

where $x_{i}, x_{j}, y_{i}, y_{j}$ are the coordinates of the $i$ and $j$ regions.

However, if we perform the calculation on all unit areas involved, we will know in which direction their forces exactly act and how strongly they affect the given unit area (Equation 10).

$$
\begin{aligned}
& D_{i}^{X}=-\sum_{j=1}^{n} \frac{W_{i} \cdot W_{j}}{d_{i j}^{c+1}} \cdot\left(x_{i}-x_{j}\right) \\
& D_{i}^{Y}=-\sum_{j=1}^{n} \frac{W_{i} \cdot W_{j}}{d_{i j}^{c+1}} \cdot\left(y_{i}-y_{j}\right)
\end{aligned}
$$

It should be noted that while in potential models, the results are modified by the introduction of "self-potential", in the examination of forces we disregard the introduction of "self- forces".

Thus, it is possible to determine the magnitude and direction of force in which other areas affect each territorial unity. The direction of the vector, which is assigned to the region, determines the attraction direction of other unit areas, while the length of the vector is proportional to magnitude of force. For the sake of mapping and illustration, we transformed the received forces into shifts proportional to them in the following way (Equation 11 and 12):

$$
\begin{aligned}
& x_{i}^{\bmod }=x_{i}+\left(\begin{array}{c}
D_{i}^{X} * \frac{x^{\max }}{x^{\min }} * k \frac{1}{D^{X_{\max }}} \\
D^{X_{\min }}
\end{array}\right) \\
& y_{i}^{\bmod }=y_{i}+\left(D_{i}^{Y *} \frac{y^{\max }}{y^{\min }} * k \frac{1}{\frac{D^{Y_{\max }}}{D^{Y_{\min }}}}\right)
\end{aligned}
$$

where $X_{i}{ }^{\text {mod }}$ and $Y_{i}{ }^{\text {mod }}$ are the coordinates of new points modified by the gravitational force, $x$ and $y$ are the coordinates of the original point set, the extreme values of which are $x^{\max }, y^{\max }, a x^{\min }, y^{\min }, D_{i}$ is the force along the $x$ and $y$ axes, $\mathrm{k}$ is a constant and in this case it is 0.5 . This has the effect of normalizing the data magnitudes.

We assume that in our model the amount of interactions between the „masses" is the same as in Equation 7, and based on the superposition principle, it can be calculated for a given region by Equation 10 . The new model cannot directly be compared with transport- 
geographical data, but the results compared with traffic data in potential models to verify our model (Kincses-Tóth 2011).

Our model is a kind of complement to the potential models that ensures a deeper insight into them. In the following sections of this study we intend to communicate some significant results of this model.

\section{Application of two-dimensional regression}

The point set obtained by the gravitational calculation $\left(W_{i}\right.$ is the gross income serving as basis of the personal income tax, population, tax payers, dwellings built, local taxes, number of active corporations and unincorporated enterprises of the $i$ micro-region in Hungary, $d_{i j}$ is the distance between $i$ and $j$ micro-regions), is worth comparing with the baseline point set, that is, with the actual real-world geographic coordinates and examining how the space is changed and distorted by the field of force. The comparison, of course, can be done by a simple cartographic representation, but with such a large number of points, it is not really promising good results. It is much better to use a twodimensional regression.

The two-dimensional regression is one the methods of comparing partial shapes. The comparison is possible only if one of the point coordinates in the coordinate systems differing from each other is transformed to another coordinate system by an appropriate rate of displacement, rotation and scaling. Thus, it is possible to determine the degree of local and global similarities of shapes as well as their differences that are based on the unique and aggregated differences between the points of the shapes transformed into a common coordinate system. The method was developed by Tobler, who published a study describing this procedure in 1994 after the precedents of the 60s and 70s (Tobler, $1961,1965,1978,1994)$. There are many examples using this procedure, which are not necessarily motivated by geographic issues (Kare-Samal-Marx 2010, SymingtonBrunsdon-Charlton 2002, Nakaya 2010).

As for the equation relating to the calculation of the Euclidean version, see Tobler 1994, Friedmann-Kohler 2003, Dusek 2011. 
The equation of the two dimensional regression of Euclidean

\begin{tabular}{|c|c|}
\hline $\begin{array}{l}\text { 1. Equation of the } \\
\text { regression }\end{array}$ & $\left(\begin{array}{l}A^{\prime} \\
B^{\prime}\end{array}\right)=\left(\begin{array}{l}\alpha_{1} \\
\alpha_{2}\end{array}\right)+\left(\begin{array}{cc}\beta_{1} & -\beta_{2} \\
\beta_{2} & \beta_{1}\end{array}\right) *\left(\begin{array}{l}X \\
Y\end{array}\right)$ \\
\hline 2. Scale difference & $\Phi=\sqrt{\beta_{1}^{2}+\beta_{2}^{2}}$ \\
\hline 3. Rotation & $\Theta=\tan ^{-1}\left(\frac{\beta_{2}}{\beta_{1}}\right)$ \\
\hline 4.Calculation of $\beta_{1}$ & $\beta_{1}=\frac{\sum\left(a_{i}-\bar{a}\right) *\left(x_{i}-\bar{x}\right)+\sum\left(b_{i}-\bar{b}\right) *\left(y_{i}-\bar{y}\right)}{\sum\left(x_{i}-\bar{x}\right)^{2}+\sum\left(y_{i}-\bar{y}\right)^{2}}$ \\
\hline 5.Calculation of $\beta_{2}$ & $\beta_{2}=\frac{\sum\left(b_{i}-\bar{b}\right) *\left(x_{i}-\bar{x}\right)-\sum\left(a_{i}-\bar{a}\right)^{*}\left(y_{i}-\bar{y}\right)}{\sum\left(x_{i}-\bar{x}\right)^{2}+\sum(y-\bar{y})^{2}}$ \\
\hline 6. Horizontal shift & $\alpha_{1}=\bar{a}-\beta_{1} * \bar{x}+\beta_{2} * \bar{y}$ \\
\hline 7. Vertical shift & $\alpha_{2}=\bar{b}-\beta_{2} * \bar{x}-\beta_{1} * \bar{y}$ \\
\hline $\begin{array}{l}\text { 8. Correlation based on } \\
\text { error terms }\end{array}$ & $\mathrm{r}=\sqrt{1-\frac{\sum\left[\left(\mathrm{a}_{\mathrm{i}}-\mathrm{a}_{\mathrm{i}}^{\prime}\right)^{2}+\left(\mathrm{b}_{\mathrm{i}}-\mathrm{b}_{\mathrm{i}}^{\prime}\right)^{2}\right]}{\sum\left[\left(\mathrm{a}_{\mathrm{i}}-\overline{\mathrm{a}}\right)^{2}+\left(\mathrm{b}_{\mathrm{i}}-\overline{\mathrm{b}}\right)^{2}\right]}}$ \\
\hline $\begin{array}{l}\text { 9. Breakdown of the } \\
\text { square sum of the } \\
\text { difference }\end{array}$ & $\begin{array}{l}\sum\left[\left(a_{i}-\bar{a}\right)^{2}+\left(b_{i}-\bar{b}\right)^{2}\right]=\sum\left[\left(a_{i}^{\prime}-\bar{a}\right)^{2}+\left(b_{i}^{\prime}-\bar{b}\right)^{2}\right]+\sum\left[\left(a_{i}-a_{i}^{\prime}\right)^{2}+\left(b_{i}-b_{i}^{\prime}\right)^{2}\right] \\
\operatorname{SST}=S S R+\operatorname{SSE}\end{array}$ \\
\hline 10. Calculation of A' & $A^{\prime}=\alpha_{1}+\beta_{1}(X)-\beta_{2}(Y)$ \\
\hline 11. Calculation of $\mathrm{B}^{\prime}$ & $B^{\prime}=\alpha_{2}+\beta_{2}(X)+\beta_{1}(Y)$ \\
\hline
\end{tabular}

Source: Tobler (1994) and Friedman, Kohler (2003) based on Dusek 2011 p.14.

Where $x$ and $y$ are the coordinates of independent shapes, $a$ and $b$ are the coordinates of dependent shapes, $a^{\prime}$ and $b^{\prime}$ represent the coordinates of dependent shapes in the system of independent shapes. $\alpha_{1}$ determines the measure of horizontal shift, while $\alpha_{2}$ determines the measure of vertical shift. $\beta_{1}$ and $\beta_{2}$ are the scalar difference and $(\Phi)$ and $(\Theta)$ determine the angle of shifting.

SST is the total square sum of difference. SSR is the square sum of difference explained by regression. SSE is the square sum of difference not explained by the regression (residual). Further details about the background of the two-dimensional regression can be seen in Dusek (2011) p. 14-15. 
Bi-dimensional regression between the gravitational and the geographical space under personal income tax

\begin{tabular}{c|c|c|c|r|r|r|r}
\hline Year & $\mathrm{r}$ & $\alpha_{1}$ & $\alpha_{2}$ & $\beta_{1}$ & $\beta_{2}$ & $\Phi$ & $\Theta$ \\
\hline 2000 & 0,942 & 6304,48 & 2017,44 & 0,99 & 0,00 & 0,99 & 0,00 \\
2005 & 0,942 & 6030,56 & 2012,23 & 0,99 & 0,00 & 0,99 & 0,00 \\
2010 & 0,941 & 8026,79 & 2632,29 & 0,99 & 0,00 & 0,99 & 0,00 \\
\cline { 2 - 6 } & Year & SST, \% & SSR, \% & SSE, \% \\
\cline { 2 - 6 } & 2000 & 100,00 & 98,73 & 1,27 \\
& 2005 & 100,00 & 98,74 & 1,26 \\
& 2010 & 100,00 & 98,69 & 1,31 & \\
\end{tabular}

Our results show that there is a strong relation between the two point systems; the transformed version from the original point set can be obtained without using rotation $(\Theta=0)$. Essential ratio difference between the two shapes was not observed. Comparing the obtained results, it is obvious that the set of points behaves like a single-centre midpoint similarity, when it is diminished. This means that only the attractive force of Budapest can be determined at a national level.

Bi-dimensional regression between the gravitational and the geographical space by population

\begin{tabular}{|c|c|c|c|c|c|c|c|}
\hline Year & $\mathrm{r}$ & $\alpha 1$ & $\alpha 2$ & $\beta 1$ & $\beta 2$ & $\Phi$ & $\Theta$ \\
\hline 2000 & 0,937 & 17095 & 5208 & 0,97 & 0,00 & 0,99 & 0,00 \\
\hline 2005 & 0,938 & 15536 & 4808 & 0,98 & 0,00 & 0,98 & 0,00 \\
\hline \multirow[t]{5}{*}{2010} & 0,938 & 13723 & 4303 & 0,98 & 0,00 & 0,98 & 0,00 \\
\hline & & Year & SST, \% & SSR, \% & SSE, $\%$ & & \\
\hline & & 2000 & 100,00 & 98,48 & 1,51 & & \\
\hline & & 2005 & 100,00 & 98,53 & 1,47 & & \\
\hline & & 2010 & 100,00 & 98,57 & 1,43 & & \\
\hline
\end{tabular}

Bi-dimensional regression between the gravitational and

Table 4 the geographical space by the number of tax payers

\begin{tabular}{c|c|c|c|c|c|c|c}
\hline Year & $\mathrm{r}$ & $\alpha 1$ & $\alpha 2$ & $\beta 1$ & $\beta 2$ & $\Phi$ & $\Theta$ \\
\hline 2000 & 0,937 & 14390 & 4476 & 0,98 & 0,00 & 0,98 & 0,00 \\
2005 & 0,937 & 14199 & 4458 & 0,98 & 0,00 & 0,98 & 0,00 \\
2010 & 0,938 & 14245 & 4492 & 0,98 & 0,00 & 0,98 & 0,00 \\
\cline { 3 - 7 } & \multicolumn{2}{c}{ Year } & SST (\%) & SSR (\%) & SSE (\%) \\
\cline { 3 - 7 } & 2000 & 100,00 & 98,53 & 1,47 \\
\\
\cline { 3 - 7 } & 2005 & 100,00 & 98,53 & 1,47 \\
& 2010 & 100,00 & 98,54 & 1,46 & \\
\end{tabular}


Bi-dimensional regression between the gravitational and the geographical space by the number of dwellings built

\begin{tabular}{|c|c|c|c|c|c|c|c|}
\hline Year & $\mathrm{r}$ & $\alpha 1$ & $\alpha 2$ & $\beta 1$ & $\beta 2$ & $\Phi$ & $\Theta$ \\
\hline 2000 & 0,940 & 8387 & 2743 & 0,99 & 0,00 & 0,99 & 0,00 \\
\hline 2005 & 0,940 & 7035 & 2314 & 0,99 & 0,00 & 0,99 & 0,00 \\
\hline \multirow[t]{5}{*}{2010} & 0,941 & 4531 & 1524 & 0,99 & 0,00 & 0,99 & 0,00 \\
\hline & & Year & $\mathrm{SST}, \%$ & SSR, $\%$ & SSE, $\%$ & & \\
\hline & & 2000 & 100,00 & 98,66 & 1,34 & & \\
\hline & & 2005 & 100,00 & 98,64 & 1,36 & & \\
\hline & & 2010 & 100,00 & 98,69 & 1,31 & & \\
\hline
\end{tabular}

Bi-dimensional regression between the gravitational and

Table 6 the geographical space by local taxes

\begin{tabular}{c|c|c|c|c|c|c|c}
\hline Year & $\mathrm{r}$ & $\alpha 1$ & $\alpha 2$ & $\beta 1$ & $\beta 2$ & $\Phi$ & $\Theta$ \\
\hline 2000 & 0,945 & 2333 & 774 & 1,00 & 0,00 & 1,00 & 0,00 \\
2005 & 0,944 & 2816 & 924 & 1,00 & 0,00 & 1,00 & 0,00 \\
2010 & 0,945 & 2679 & 883 & 1,00 & 0,00 & 1,00 & 0,00 \\
\cline { 3 - 7 } & \multicolumn{2}{c}{ Year } & SST, \% & SSR, \% & SSE, \% \\
\cline { 2 - 7 } & 2000 & 100,00 & 98,84 & 1,16 \\
& 2005 & 100,00 & 98,82 & 1,18 & \\
& 2010 & 100,00 & 98,84 & 1,16 &
\end{tabular}

Bi-dimensional regression between the gravitational and

Table 7

the geographical space by the number of active enterprises

\begin{tabular}{|c|c|c|c|c|c|c|c|}
\hline Year & $\mathrm{r}$ & $\alpha 1$ & $\alpha 2$ & $\beta 1$ & $\beta 2$ & $\Phi$ & $\Theta$ \\
\hline 2000 & 0,941 & 7870 & 2534 & 0,99 & 0,00 & 0,99 & 0,00 \\
\hline 2005 & 0,942 & 6984 & 2272 & 0,99 & 0,00 & 0,99 & 0,00 \\
\hline \multirow[t]{5}{*}{2010} & 0,942 & 6265 & 2052 & 0,99 & 0,00 & 0,99 & 0,00 \\
\hline & & Year & $\mathrm{SST}, \%$ & SSR, \% & $\mathrm{SSE}, \%$ & & \\
\hline & & 2000 & 100,00 & 98,69 & 1,31 & & \\
\hline & & 2005 & 100,00 & 98,72 & 1,28 & & \\
\hline & & 2010 & 100,00 & 98,74 & 1,26 & & \\
\hline
\end{tabular}

The observed pairs of points are strongly correlated with each other. The analysis of local taxes showed the strongest correlation. The values of betal may provide the most important relationship. These unambiguously indicate an east-west divide in Hungary.

\section{Map display and direction analyses}

The aforementioned statement can be illustrated by a map display of a two-dimensional regression. The Darcy program can be used in the application (http://www.spatialmodelling.info/Darcy-2-module-decomparaison). 
The square grid attached onto the shape-dependent coordinate system and its interpolated modified position further generalizes the information received from the participating points.

The arrows in Figures 2 and 3 show the directions of the shifts, while the colouring illustrates the type of distortion. The warm colours express the divergent forces of the area, which are considered to be the most important gravitational displacements.

The areas illustrated in green and its shades represent just the opposite, namely the most important nodes of gravity.

The data in Table 2 shows that the space shaped by the gravitational model causes only a slight distortion compared to the geographic space. The magnitude of vertical and horizontal displacements increased slightly in 2010.

Practically, the maps produced by Darcy software verify this (Figure 2 and Figure 3). It can be seen that the capital of Hungary is Hungary's main centre of gravity, the centre towards which the largest power is attracted. The regional centres like Györ, Pécs, Szeged, Debrecen are also gravity nodes. The national role of regional centres is weak. In the area of Budapest a gravity fault line emerges.

The reason for this phenomenon is that the Hungarian capital attracts all the microregions, while very weak forces are applied to Budapest compared to its mass.

The map also illustrates that the regular force fields are the major transport corridors, namely they are slightly distorted due to highways. Between 2000 and 2010, the significance of green-marked gravitational nodes increased. The comparison of the two maps clearly shows the intensification of regional differences.

Visualizing the gravity field on the basis of incomes, 2000

Figure 2

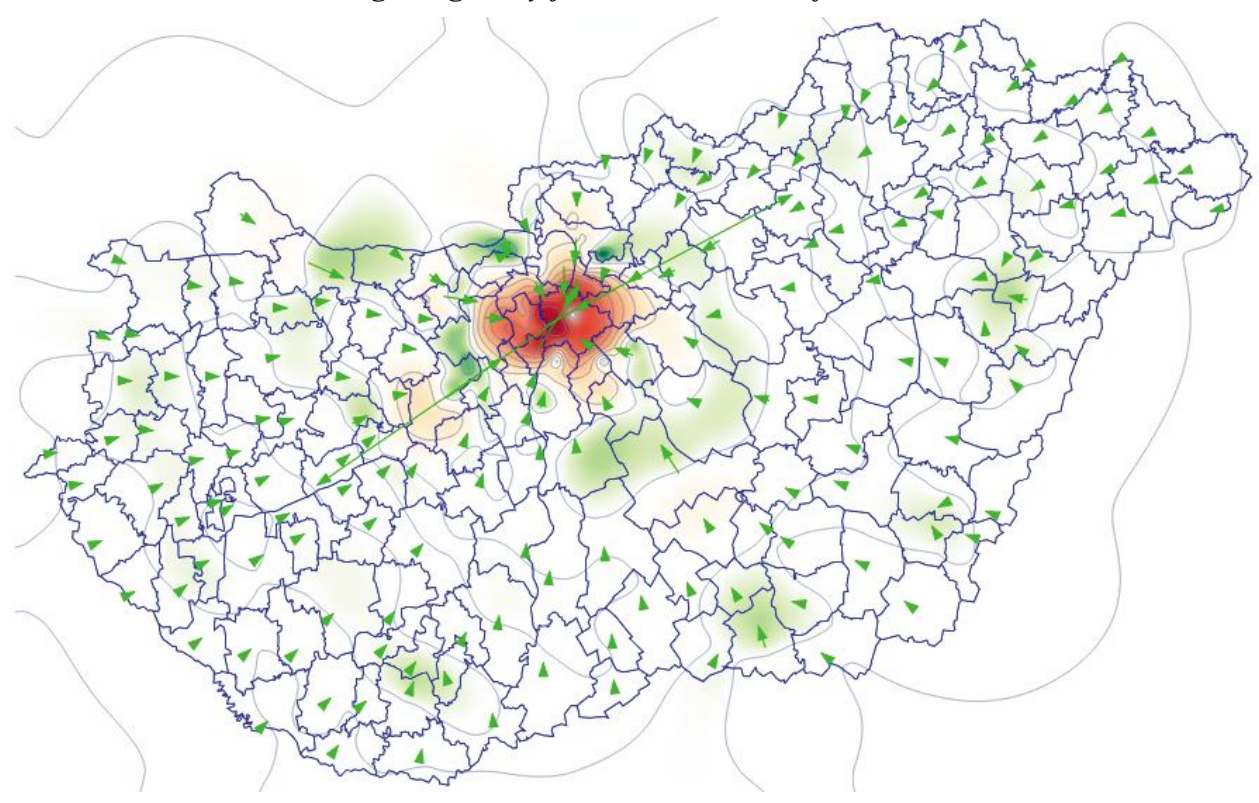


Visualizing the gravity field on the basis of incomes, 2010

Figure 3

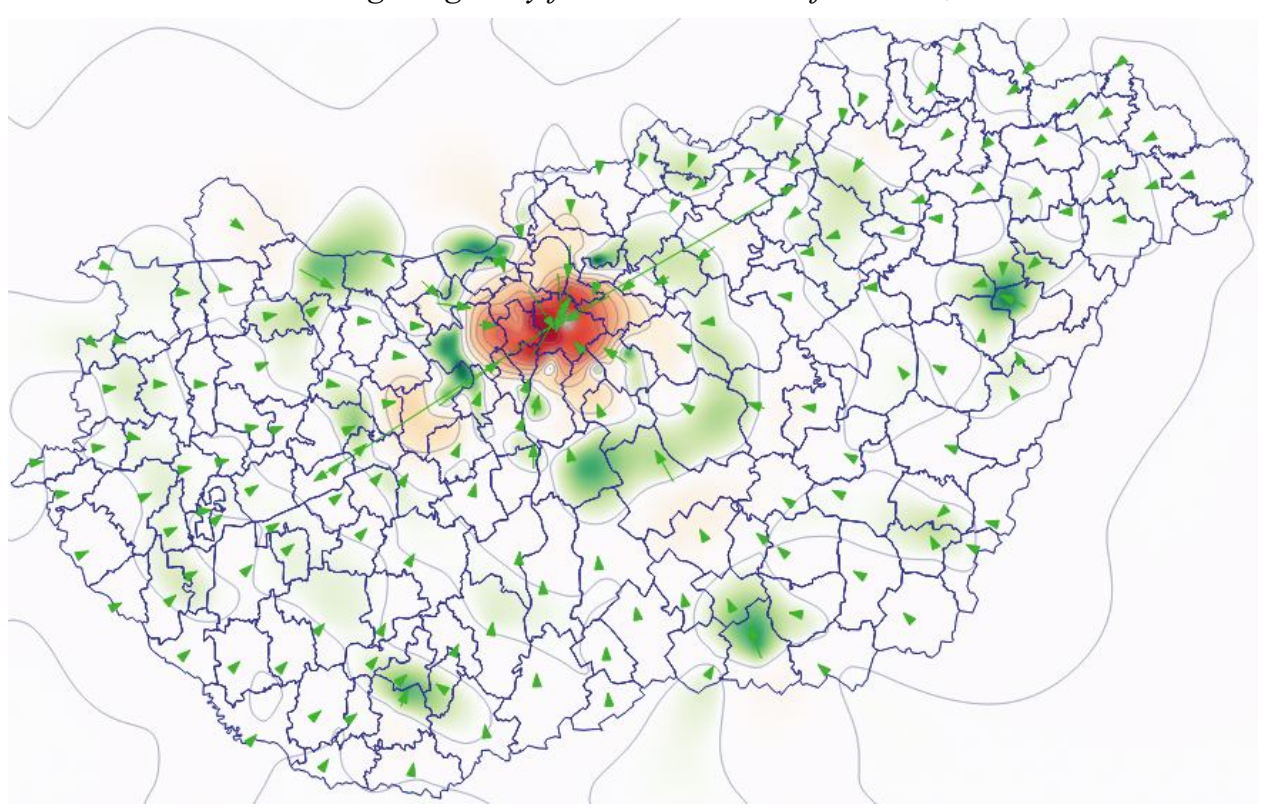

We try to analyze what socio-economic factors resulted in the development conditions of 2010 through using the above introduced indicators to model how the gravity field changed. The population number in the micro regions of the western section of the Budapest agglomeration sharply fell clearly indicating a gravity breaking point due to the reversal of previously prevailing suburbanization processes. There are similar depressed areas in the micro regions of Eger and Mezökövesd. The relationship of the micro regions of Debrecen and Balmazújváros showed the strongest gravity node. In contrast with this, there are only smaller sub centres at the south western tip of Lake Balaton and at the node determined by the micro regions of Esztergom, Tatabánya and Bicske.

Concerning the number of taxpayers, Budapest has a clear 'node position' and there is another, related, gravity centre in the south western tip of Lake Balaton. There are smaller quasi sub centres, on the one hand, around some regional centres (Györ, Debrecen) and, on the other hand, in some more dynamic micro regions (Tatabánya). The most significant divide is between the node in the surroundings of Lake Balaton and the micro regions lying south west of that. In this respect, there are relatively few significant 'fault lines' in the gravity field. 
Changes in the gravity field based on population figures, 2000-2010

Figure 4

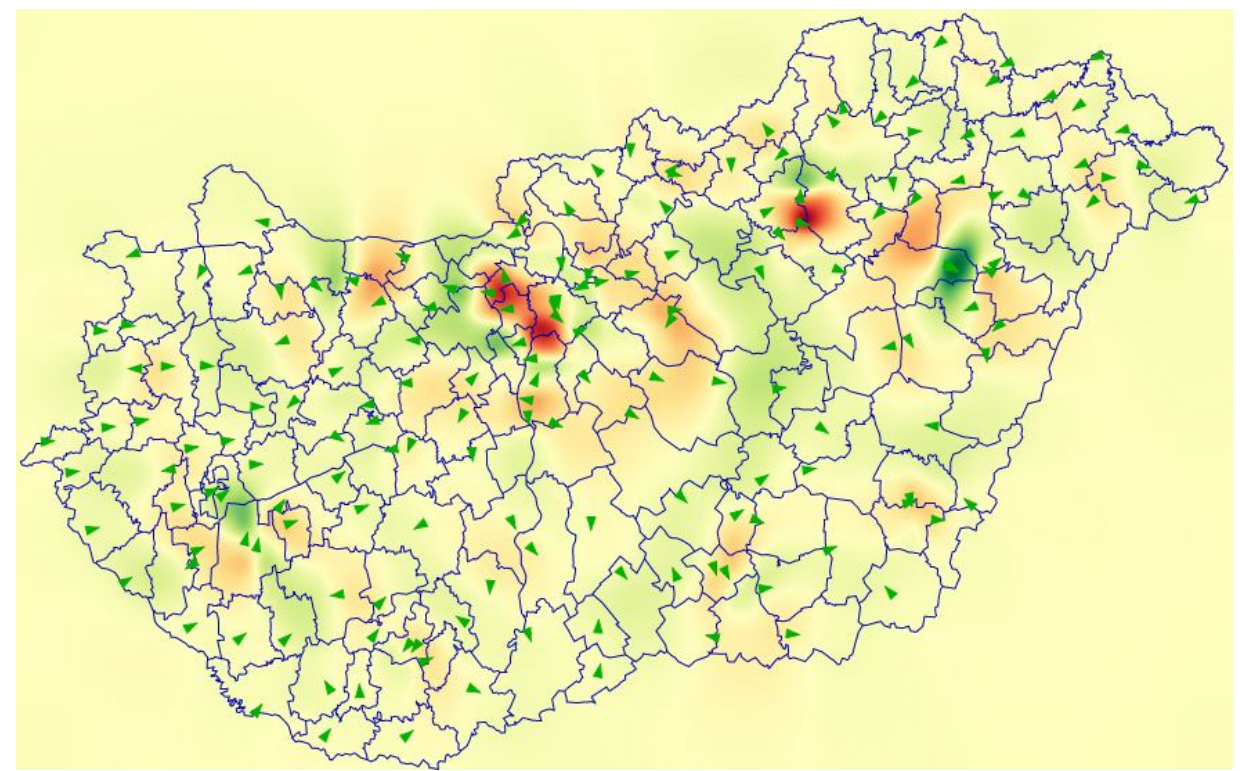

Changes in the gravity field based on the number of tax payers, 2000-2010

Figure 5

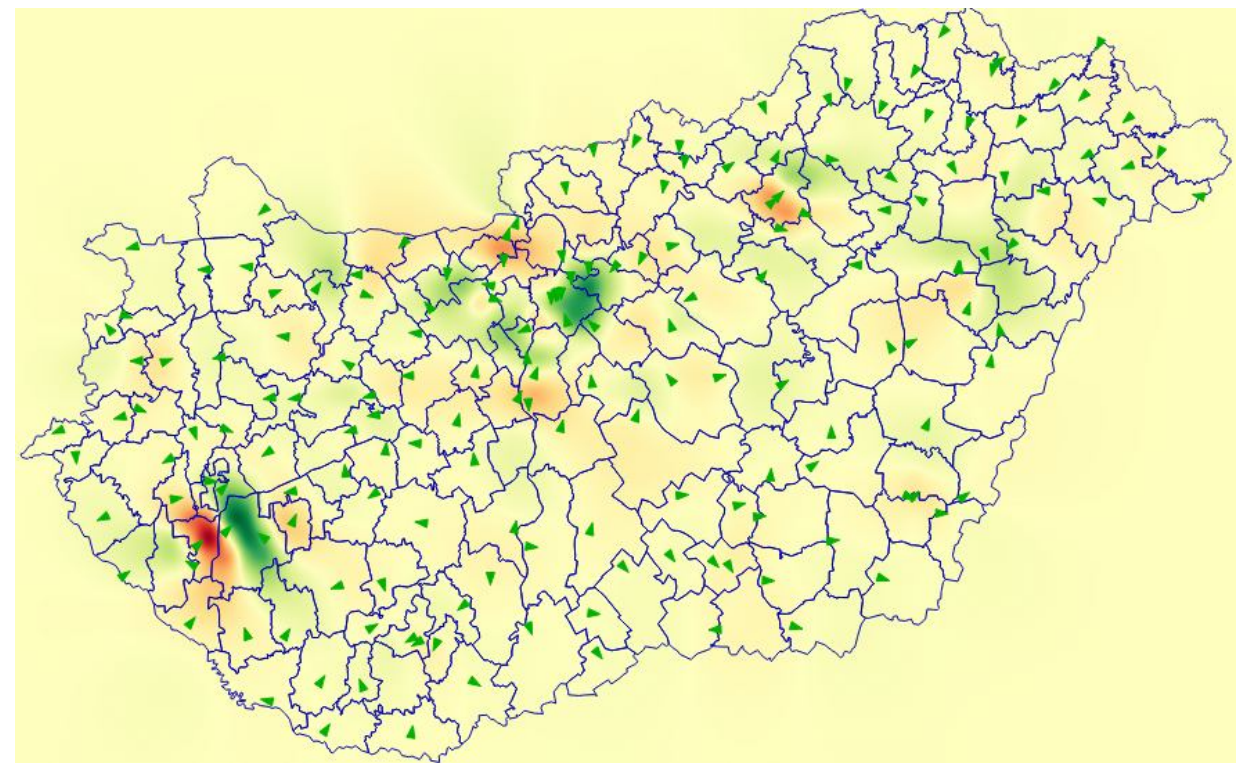

In comparison with the previous ones, a slightly different picture emerges in the number of dwellings built. On the one hand there are several gravity centres and breaking points. A significant centre can be seen in the northern part of the agglomeration of 
Budapest. Based on the breaking point lying south of this centre we can say that the rise in the number of dwellings built was implemented at the expense of the capital city. It reflects the constantly changing processes of suburbanization. There is a gravity centre at the regional hub of Miskolc, as well as south of Budapest and in the surroundings of the western tip of Lake Balaton (micro regions of Hévíz and Keszthely as well as the microregion of Nagyatád). The reasons may be different in case of these micro-regions, i.e. tourism plays a determining role in the former ones, while in case of the latter one - as we will show among active enterprises - it results from the favourable effects of industry.

Changes in the gravity field based on the number of dwellings built, 2000-2010

Figure 6

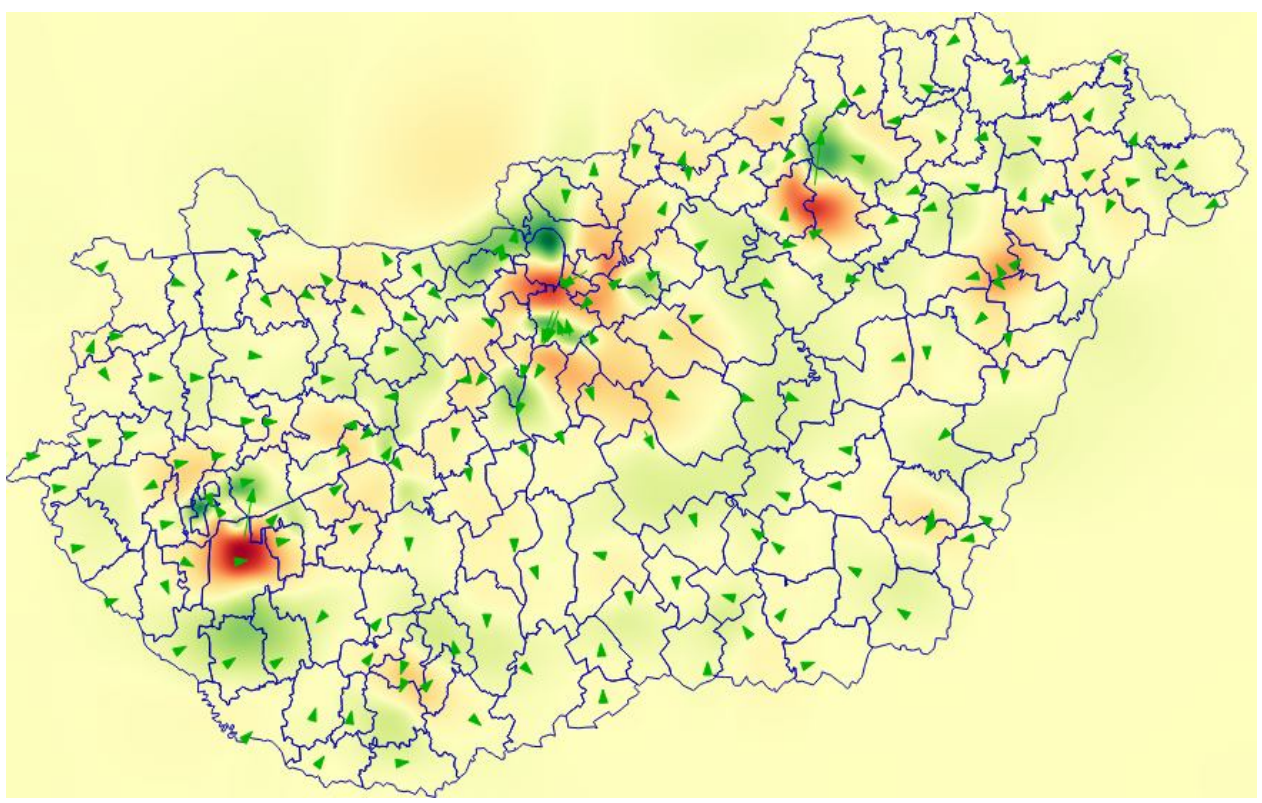

Maybe the gravity map of local taxes shows the most varied patterns. In this respect, Budapest and the regional centres can be identified as the most important nodes, but the micro regions of serious industrial base, e.g. those of Esztergom and Székesfehérvár deserve attention as well. The most significant gravity 'fault line' is between these micro regions and the agglomeration of Budapest. The previously mentioned micro region of Hévíz is another gravity node in this respect. 
Changes in the gravity field based on local taxes, 2000-2010

Figure 7

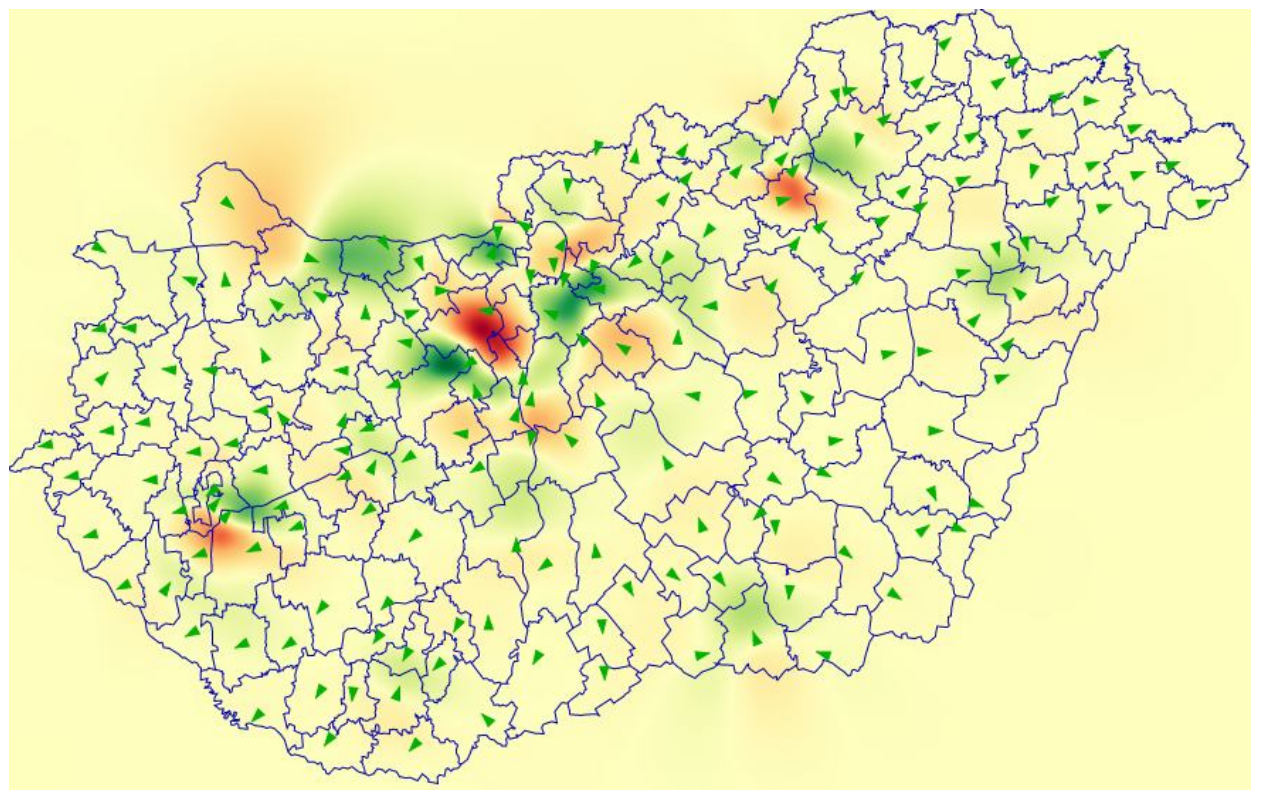

Figure 8

Changes in the gravity field based on the number of active enterprises, 2000-2010

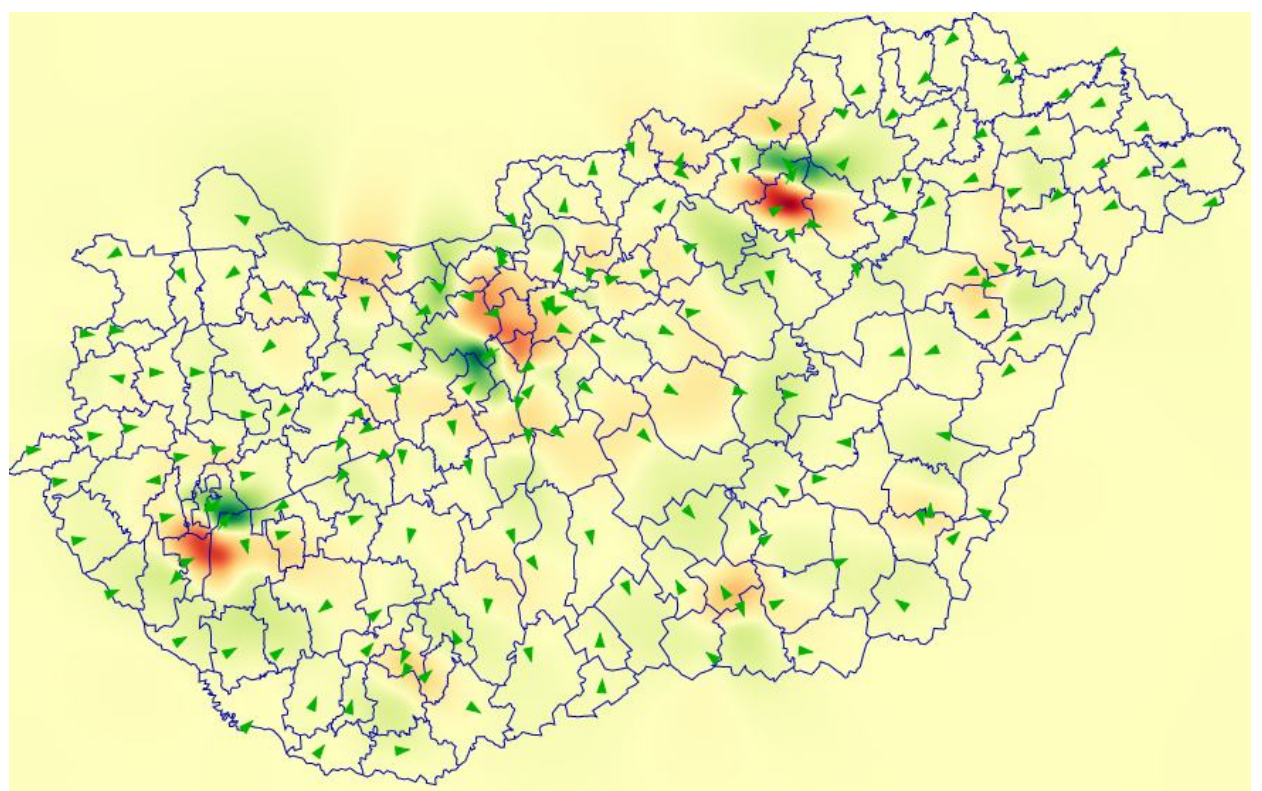

As for the number of active enterprises, the micro regions of Hévíz, Székesfehérvár, Miskolc and Eger play a central role. There are another, smaller centres of local 
importance, e.g. the micro region of Nagyatád with the surrounding areas, which is separated by a sharp breaking point from the micro regions of Keszthely and Hévíz.

\section{Summary}

In our study we made an attempt to introduce the potential and unexplored areas of gravitational models and problems of their interpretation by expanding and extending the methodology. The forces applied were illustrated by using the income tax base as weights in micro-regions of Hungary. On the basis of the model, the result in line with the experience illustrated that Budapest has no counterweight in Hungary and the local central areas are weak. However, the presence of stable local centres is detectable in Debrecen, Miskolc, Nyíregyháza, Szeged and Pécs micro-regions.

There are several indicators to highlight and thoroughly analyze what socio-economic processes are behind a basic change in the spatial structure.

\section{REFERENCES}

Budó, Á. (1970). Experimental Physics I. National Textbook Press, Budapest.

Carey, H. C. (1858). Principles of Social Science. J.B. Lippincott \& Co., New York.

Converse P.D. (1949). New Laws of Retail Gravitation. Journal of Marketing 14 3, 379-384.

Dodd S. G. (1950). The Interactance Hypothesis. A Gravity Model Fitting Physical Masses and Human Groups. American Sociological Review 15 2, 245-256.

Dusek, T. (2003). A gravitációs modell és a gravitációs törvény összehasonlítása. Tér és Társadalom 17 (1), 41-57.

Dusek. T. (2011). Kétdimenziós regresszió a területi kutatásokban. Területi Statisztika 51 1, 11-22.

Filippo, S., Maritan, A. and Néda, Z (2012). Continuum approach for a class of mobility models, [physics.socph] 19 Jun 2012, http://arxiv.org/pdf/1206.4359.pdf

Friedman, A., Kohler, B. (2003). Bidimensional Regression: Assessing the Configural Similarity and Accuracy of Cognitive Maps and Other Two-Dimensional Data Sets. Psychological Methods, 8 4, 468491.

Geurs, KT., van Wee, B. (2004). Accessibility evaluation of land-use and transport strategies: review and research directions. Journal of Transport Geography 12 2, 127-140.

Gutierrez, J. (2001). Location, economic potential and daily accessibility: an analysis of the accessibility impact of the high-speed line Madrid-Barcelona-French border. Journal of Transport Geography 9 , 229-242.

Hammer C., Ikle, F.C. (1957). Intercity Telephone and Airline Traffic Related to Distance and the Propensity to Interact. Sociometry 20 4, 306-316.

Kare,S., Samal,A. and Marx, D. (2010). Using bidimensional regression to assess face similarity.. Machine Vision and Applications 21 3, 261-274.

Kincses, Á., Tóth, G. (2011). A potenciálmodellek geometriája. Területi Statisztika 51 1, $23-37$.

Barthélemy, M. (2011). Spatial network. Physics Reports, 499: 1-101 http://arxiv.org/abs/1010.0302.

Vieira,M., Giovani L., Vasconcelos, and Sidney R. Nagel (1993). Dynamics of spring-block models: Tuning to criticality Physical Review E. 47 4., R2221-R2224

Martinez-Zarzoso, I., Nowak-Lehmann, F. (2003). Augmented gravity model. An empirical application to Mercosur-European Union trade flows. Journal of Applied Economics 6 2, 291-316.

Mate, G., Neda, Z. and Benedek, J. (2011). Spring-Block model reveals region-like structures. PLoS ONE 6(2): e16518. doi:10.1371/journal.pone.0016518.

Nakaya, T. (2010). Statistical Inferences in Bidimensional Regression Models. Geographical Analysis 292 , $169-186$.

Reilly, W. J. (1929). Methods for the Study of Retail Relationships. University of Texas Bulletin, No. 2944 
Schürmann, C., Spiekermann, K. and Wegener, M. (1997). Accessibility Indicators. Berichte aus dem Institüt für Raumplanung 39, Dortmund, IRPUD

Stewart J. Q. (1948). Demographic Gravitation: Evidence and Applications. Sociometry 11 1-2, 31-58.

Symington, A., Charlton, M.E. and Brunsdon, C.F. (2002). Using bidimensional regression to explore map lineage Computers, Environment and Urban Systems 26 2, 201-218.

Tobler, W. R. (1961). Map Transformations of Geographic Space. PhD dissertation, Seattle, University of Washington.

Tobler, W. R. (1965). Computation of the Correspondence of Geographical Patterns. Papers of the Regional Science Association. 15 1, 131-139.

Tobler, W. R. (1970). A Computer Model Simulating Urban Growth in the Detroit Region. Economic Geography. 46 2, 234-240.

Tobler, W. R. (1978). Comparisons of Plane Forms. Geographical Analysis 10 2, 154-162.

Tobler, W. R. (1994). Bidimensional Regression. Geographical Analysis 26. 3, 187-212.

Tobler, W. R. (2004). On the First Law of Geography: A Reply Annals of the Association of American Geographers 94 2, 304-310.

Tschopp, M., Fröhlich, P., Keller, P. and Axhausen, K.W. (2003). Accessibility, Spatial Organisation and Demography in Switzerland through 1920 to 2000: First Results. 3rd Swiss Transport Research Conference Monte Verità / Ascona, March 19-21. 2003.

Willigers, J., Floor, H. and van Wee, B. (2007). Accessibility indicators for locational choice of offices: An application to the intraregional distributive effects of high-speed rail in the Netherlands. Environment Planning. A 39 9, 2086-2098.

Zipf G. K. (1949). Human Behaviour and the Principle of Least Effort: An Introduction to Human Ecology. Addison-Wesley Press, Cambridge. 